\title{
ANALISIS MODEL BISNISUSAHACOFFEE SHOP MELALUI KANVAS MODEL BISNIS DAN PETA EMPATI: STUDI KASUS PADACOFFEE SHOP DI MALANG
}

\author{
Bagus Ibnu Utama, S.E., M.B.A. \\ Program Studi Manajemen Fakultas Ekonomi dan Bisnis \\ Universitas Gajayana Malang.
}

\begin{abstract}
ABSTRAK: Persaingan dalam industri kuliner saat ini semakin marak, khususnya coffee shop. Keberadaan coffee shop seakan menjadi gaya hidup yang menjadi tren di kalangan masyarakat modern. Potensi pertumbuhan yang pesat didorong oleh bertambahnya jumlah mahasiswa yang ada di kota Malang. Hal ini dapat menjadi peluang bisnis yang sangat baik sekaligus juga akan meningkatkan persaingan antar pelaku bisnis dalam industri ini. Pertumbuhan konsumen Coffee Shop diiringi juga oleh pertumbuhan pelaku bisnis. Hal ini menjadikan persaingan Potensi pertumbuhan yang pesat ini dapat menjadi peluang bisnis yang sangat baik sekaligus juga akan meningkatkan persaingan antar pelaku bisnis dalam industri ini. Pertumbuhan konsumen Coffee Shop diiringi juga oleh pertumbuhan pelaku bisnis. Hal ini menuntut para pelaku bisnis untuk dapat memenangkan konsumen di tengah persaingan yang ketat sekaligus mengatasi kendala-kendala yang bisa terjadidi kota Malang semakin ketat.

Observasi awal peneliti menunjukkan dua hal yang menjadi kekurangan dari pelaku bisnis Coffee Shop di kota Malangyaitu kurangnya wawasan mengenai konsumen dan model bisnis yang belum terencana. Subjek dalam penelitian ini adalah para pelaku bisnis Coffee Shopdan konsumen Coffee Shopdi kota Malang. Pengumpulan data dilakukan dengan wawancara dan observasi. Metode analisis data dilakukan dengan menganalisis kanvas model bisnis dari pelaku bisnis dan menganalisis peta empati konsumen Coffee Shop. Hasil penelitian yang dapat diambil dari penelitian ini, bahwa masih kurangnya analisis yang komprehensif dalam menyusun model bisnis seperti kanvas model bisnis dan peta empati konsumen oleh pelaku bisnis Coffee Shop di kota Malang.

Kata Kunci : Coffee Shop, kanvas bisnis model, peta empati
\end{abstract}

Abstract: Competition in the culinary industry is increasingly widespread, especially coffee shop. The existence of coffee shop seems to be a lifestyle that become a trend among modern society. The potential for rapid growth is driven by the increasing number of students in Malang. It can be an excellent business opportunity as well as will increase competition among businessman in this industry. Coffee Shop consumer growth is accompanied by business growth. This makes the competition This rapid growth potential can be an excellent business opportunity as well as will increase competition among business players in this industry. Coffee Shop consumer growth is accompanied by business growth. This requires business people to be able to win consumers in the midst of intense competition while overcoming the obstacles that can occur in the city of Malang is getting tighter.

Initial observation of the researcher shows two things that become the deficiency of coffee shop business in Malang city that lack of knowledge about consumer and unplanned business model. Subjects in this study are the businessmen Coffee Shop and consumer Coffee Shop in Malang city. Data collection was done by interview and observation. Methods of data analysis is done by analyzing the canvas business model from businesmen and analyzing the map of consumer empathy of Coffee Shop. The results of this study can be drawn from this research, that there is still a lack of comprehensive analysis in formulating 
business model such as business model canvas and consumer empathy map by coffee shop business in Malangcity.

Keywords: Coffee Shop, model business canvas, empathy map

\section{PENDAHULUAN}

Minum kopi kini menjadi gaya hidup masyakarat, fenomena ini terlihat dari pesatnya perkembangan tempat-tempat yang meyajikan minuman kopi. Perubahan gaya hidup yang terjadi pada masyarakat dan pertumbuhan kelas menengah telah mendorong industri pengolahan kopi. Pertumbuhan konsumsi produk kopi olahan di dalam negeri meningkat rata-rata lebih dari 7 persen per tahun.Fenomena juga didukung dengan gaya hidup masyarakat dalam kegiatan makan di luar rumah (eating out), kegiatan ini masyakrakat senang mengkonsumsi makanan di luar rumah (Murwani, 2012). Hal ini mendorong restoran, café, coffe shop dan rumah makan mengalami pertumbuhan yang cepat. Hasil riset Qraved.com (2014), menyebutkan bahwa sepanjang tahun 2013, tercatat kunjungan orang Indonesia ke restoran, café, coffe shop dan rumah makan mencapai 380 juta kali. Menurut hasil survey Nielsen Indonesia (2009) yang dilakukan di 6 kota besar di Indonesia, yaitu Jakarta, Bandung, Semarang, Surabaya, Makasar, dan Medan menunjukkan bahwa 44\% konsumen melakukan kegiatan makan di luar rumah dengan frekuensi sebanyak 1-3 kali dalam sepekan. Survey ini juga menyebutkan bahwa masyarakt melakukan kegiatan makan diluar rumah untuk kebutuhan bersosialisasi.

Kota Malang sebagai kota terbesr kedua di Jawa Timur, mengalami pertumbuhuan yang terus berkebang. Beberapa sektor yang terlihat perkembangannya adalah sektor pariwisata, kuliner dan pendidikan. Jumlah mahasiswa yang belajar di Malang cukup banyak. Dengan banyaknya jumlah penduduk serta penambahan mahasiswa baru tiap tahunnya, membuat hal ini menjadi peluang bisnis yang potensial. Banyak sekali bisnis yang tumbuh akibat dari jumlah mahasiswa yang terus bertambah ini, baik dari sector kuliner maupun jasa, seperti rumah kos, renta, laundry, café, coffee shop, restoran, rumah makan dan lainya.

Salah satu bisnis yang mengalami perkembangan cukup pesat beberapa tahun belakangan di kota Malang adalah bisnis Coffee Shop. Sebagian warga malang menjadikan Coffee Shop sebagai gaya hidup untuk dikunjungi saat sela-sela kuliah, pulang kantor, kumpul bersama teman atau relasi, dan lainnya.Herlyana (2012), menyatakan bahwa banyak faktor yang menyebabkan Coffee Shop sebagai gaya hidup, hal ini adalah sebagai gejala dan respon dari keadaan dorongan untuk bersosialisasi. Potensipertumbuhan yang pesat ini dapat menjadi peluang bisnisyang sangat baik sekaligus jugaakanmeningkatkan persaingan antar pelaku bisnisdalam industri ini. Pertumbuhan konsumen Coffee Shop diiringi juga oleh pertumbuhan pelaku bisnis.Hal ini menuntut para pelaku bisnis untuk dapat memenangkan konsumen di tengah persaingan yang ketat sekaligus mengatasi kendala-kendala yang bisa terjadi. Dari hasil observasi awal peneliti menunjukkan dua hal yang menjadi kekurangan dari pelaku bisnis Coffee Shop di kota Malang, antara lain: 1) kurangnya wawasan mengenai konsumen; dan 2) model bisnis yang belum terencana.

Oleh karena itu, analisis model bisnis Coffee Shopyang komprehensifperlu dilakukan untuk memberikan gambaran bagi para pelaku bisnis agar dapat menangkap 
peluang dan memenangkan konsumen, serta memiliki model bisnis yang dapat bersaing dalam bisnis Coffee Shop dikota Malang.

\section{Rumusan Masalah}

1. Bagaimana model bisnis pada usaha Coffee Shop do kota Malang?

2. Apa sajakah wawasan konsumen yang perlu diketahui oleh pelaku bisnis Coffee Shop di kota Malang?

\section{Tujuan Penelitian}

1. Untuk mengetahui bagaimana model bisnis pada usaha Coffee Shop di kota Malang

2. Untuk memperoleh gambaran mengenai wawasan konsumen Coffee Shop di kota Malang

\section{KAJIAN TEORI}

\section{Pengertian Coffee Shop}

Keputusan Menteri Pariwisata, Pos dan Telekomunikasi No.KN.73/PVVI05/MPPT-85 tentang Peraturan usaha Rumah Makan, menyebutkan bahwa yang dimaksud dengan usaha Jasa Pangan yaitu : "Suatu usaha yang menyediakan jasa pelayanan makanan dan minuman yang dikelola secara komersial". Coffee Shop sedniri Merupakan tempat makan dan minum yang menyuguhkan suasana santaitanpa aturan yang mengikat dan biasanya menyuguhkan racikan kopi sebagaimenu spesial di luar makanan kecil atau makanan siap saji. Dalam Kamus Besar Bahasa Indonesia, Coffee Shopadalah suatu tempat (kedai) yang menyajikanolahan kopiespreso dan kudapan kecil.

\section{Definisi Model Bisnis}

Model bisnis merupakan suatu pengganbaran dari hubungan antara keunggulan dan sumber daya yang dimiliki oleh perusahaan serta kegiatan yang dilakukan untuk mengakuisisi dan menciptakan nilai, yang membuat perusahaan mampu menghasilkan laba (PPM Manajemen, 2012). Model bisnis digunakan perusahaan sebagai alat dalam perumusan strategi bisnis perusahaan.

\section{Kanvas Model Bisnis (Business Model Canvas)}

Kanvas Model Bisnis adalah alat untuk menggambarkan bagaimana perusahaan membuat, menggambarkan, dan memvisualisasikan suatu model bisnismelalui penggambaran elemen inti dalam sebuah bisnis. Osterwalder dan Pigneur, 2010 menyebutkan bahwa Kanvas model bisnis terdiri dari 9 komponen yang di sebut 9 Blok Bangunan. Kesembilan komponen ini adalah: 1) Nilai Proposisi; 2) Segmen Pelanggan; 3) Saluran Pelanggan; 4) Hubungan Pelanggan; 5) Pendapatan; 6) Aktifitas Kunci; 7) Sumber daya Kunci; 8) Kemitraan Kunci; 9)Struktur Biaya

\section{Peta Empati (Emphaty Map)}

Salah satu tolak ukur yang sering digunakan dalam mengukur kesuksesan sebuah bisnis adalah kepuasan pelanggan. Kotler \& Keller (2007:177), pelanggan akan terpuaskan apabila kinerja yang dihasilkan sebuah produk melebihi harapan. Kepuasan konsumen dapat dicapai jika perusahaan mengetahui keinginan konsumen. Sehingga perusahaan perlu untuk menganalisis hal-hal yang diinginkan oleh konsumen. 
Empathy mapadalah alat yang dapat digunakan untuk mengetahui lebih dalam halhal mengenai konsumen berdasarkan apa yang konsumen lihat, dengar, pikirkan dan rasakan, katakan dan lakukan, apa yang menjadi kerugian atau halangan yang dirasakan, serta keuntungan apa yang didapat oleh konsumen (Osterwalder dan Pigneur, 2010). Empathy map digunakan sebagai alat bantu dalam proses wawancara untuk mendapatkan informasi dari konsumen. Informasi-informasi tersebut akan menyajikan gambaran perliaku dan karakteristik konsumen yang kemudian digunakan dalam menyusun model bisnis.

\section{METODE PENELITIAN}

Penelitian ini merupakan penelitian kualitatif, dimana penulis akan menjelaskan informasi melalui kata-kata lisan dan tertulis, serta pengamatan terhadap tingkah laku dari subyek penelitian (Taylor dan Bogdan, 1984). Penelitian ini mendeskripsikan atau merekonstruksi hasil wawancara mendalam dengan sampel penelitian sehingga memberikan gambaran berguna dalam menggambarkan model bisnis usaha Coffee Shop.

\section{Populasi dan sampel}

Penelitian ini menetapkan pelaku bisnis Coffee Shop di kota Malang dan konsumenCoffee Shop sebagai populasi. Dari populasi tersebut kemudian ditarik beberapa sampel yang sesuai dengan kriteria yang dibuat peneliti berdasarkan tujuan penelitian. Kriteria yang dimaksud yaitu:

Pelaku bisnis:

1. Bidang bisnis pada usaha Coffee Shop

2. Berdomisili di kota Maang

3. Telah berbisnis sekurang-kurangnya 5 tahun. Pemilihan ini dianggap bisnis tersebut telah memiliki pengalaman dan sistem yang cukup baik.

\section{Konsumen:}

1. Usia 18-35. Pemilihan usia ini sesuai dengan target market Coffee Shop, serta dianggap telah cukup dewasa dan rasional dalam menjawab peertanyaan wawancara

2. Berdomisili di kota Malang

3. Memiliki tingkat ekonomi menengah

4. Pernah berkunjung ke Coffee Shop

\section{Sumber dan Metode Pengumpulan Data}

\section{Data Primer}

Data diperoleh melalui observasi dan wawancara kepada konsumen dan pelaku bisnis Coffee Shop yang sudah ada. Observasi dilakukan selama satu minggu dengan mengamati pengunjung, produk dan layanan rumah makan tersebut. Sementara, wawancara dilakukan pada dua objek, wawancara pertama dilakukan pada 30 konsumen Coffee Shop, untuk memperoleh gambaran wawasan konsumen.Wawancara kedua dilakukan pada pelaku bisnis Coffee Shop yaitu Telescope Coffee dan DW Coffee Shop, untuk mendapat gambaran umum model bisnis usaha Coffee Shop.

2. Data Sekunder 
Data sekunder diperoleh dengan mengumpulkan data dari jurnal, buku teori, website, dan lembaga pemerintahan, yang berkaitan dengan analisa model bisnis usaha Coffee Shop.

\section{Teknik Analisis Data}

Pertama, model bisnis kanvas digunakan sebagai penggambaran bagaimana model bisnis dari usaha Coffee Shop yang sudah ada. Kedua, peta empati digunakan untuk mengetahui bagaimana wawasan konsumen mengenai Coffee Shopberdasarkan dari apa yang dilihat, didengar, dipikirkan dan dirasakan, dikatakan dan dilakukan, kekecewaan dan keuntungan yang diperoleh.

\section{HASIL DAN PEMBAHASAN} Analisa Kanvas Model Bisnis

Berdasarkan wawancara yang dilakukan dengan pelaku bisnis Coffee Shop, maka disusunlah Model bisnis usaha Coffee Shop dengan menganalisis kanvas model bisnis dari bisnis Coffee Shop yang sudah ada, yaitu Telesope Coffee dan DW Coffee Shop.

1. Kanvas Model Bisnis Telescope Coffee

a. Segmen Pelanggan (Customer Segment)

Segmen pelanggan yang menjadi target dari elescope Coffee lebih kepada mahasiswa yang berusia 18-23 tahun, ekonomi menengah, penggemar fanatik kopi, menginginkan tempat untuk "nongkrong" dengan teman. Pemilik dari Coffee Shop ini menyatakan bahwa target pasar ini disasar karena memiliki jumlah konsmen yang banyak dan potensial.

b. Proposisi Nilai (Value Propositon)

Telescope Coffee memberikan value kepada konsumennya dengan beberapa penwaran, antara lain: 1) pengolahan dan penyeduhan kopi yang baik sehingga menghasilkan minuman kopi yang berkualitas; 2) tempat kedai kopi yang nyaman; 3) harga yang murah dan terjangkau oleh kondisi ekonomi mahasiswa.

c. Saluran Pelanggan (Channel)

Saluranyang digunakan adalah dengan menyediakan outlet atau kedai sendiri. Pendirian kedai bertujuan agar konsumen mudah memperoleh produk. Kedai didesain untuk memberi kenyamanan pada konsumen, sehingga konsumen akan merasa nyaman untuk nogkrong bersama teman.

d. Hubungan Pelanggan (Customer Relatonship)

Dalam membina hubungan dengan konsumen, Telescope Coffee memanfaatkan sarana media sosial. Dengan memposting hal-hal baru ataupun lama yang terjadi di kedai pada intagram, kemudian berinteraksi dengan konsumen melalui kolom chating yag tersedia. Hal ini dilakukan oleh pemilik Telescope Coffee sebagai bentuk dari retensi dan akusisi konsumen, dengan efektif dan efisien.

e. Arus Pendapatan (Revenue Stream) 
Pendapatan Telescope Coffee berasal dari penjualan aset, yang terdiri dari penjualan makanan dan minuman serta penjualan biji kopi. Terdapat dua jenis penjualan aset yaitu penjualan langsung pada gerai dan penjualan melalui pesanan.

f. Sumber Daya Kunci (Key Resoures)

Sumber daya kunci dari Telesope Coffee antara lain:1) kebun kopi, untuk memasok kebutuhan beberapa bahan baku kopi; 2)coffee roaster; 3) barista dan karyawan yang terlatih; 3) bangunan kedai; 4) sumber daya financial

g. Aktifitas Kunci (Key Ativities)

Beberapa hal yang menjadi aktifitas kunci dari Telescope Coffee adalah: 1) proses panen dan produksi biji kopi; 2) proses produksi produk menu; 3) kegiatan pemasaran; 4) pengantaran pesanan kopi.

h. Kemitraan Kunci (Key Partner)

Telescope Coffee menjalin kerjasama dengan petani di sekitar perkebunan kopi untuk mendapatkan hasil panen yang baik. Selain itu hubungan kerjasama juga dijalin dengan akun-akun sosial media yang memiliki jumlah followers yang tinggi.

i. Struktur Biaya (Cost Struscture)

Telescope Coffee memiliki kebijakan untuk memilah struktur biayanya dengan tujuan agar tercipta efisensi dan efektifitas biaya. Struktur biaya ini dibagi menjadi biaya produksi, biaya operasional, dan biaya pemasaran.

2. Kanvas Model Bisnis DW Coffee Shop

a. Segmen Pelanggan (Customer Segment)

Target dari Segmen pelanggan DW Coffee Shop adalah laki-laki, berusia 2026 tahun, mahasiswa atau peerja, komunitas, ekonomi menengah, peminum kopi, menginginkan tempat untuk berdiskusi, bekerja, dan berkumpul dengan teman, kolega, atau anggota komunitas. Target konsumen ini dianggap sebagai target yang potensial, pemilik DW Coffee Shop menyebutkan bahwa dewasa ini sebagian orang lebih senang berkumpul, bekerja, dan berkomunitas di tempat-tempat yang nyaman seperti Coffee Shop.

b. Proposisi Nilai (Value Propositon)

DW Coffee Shop menawarkan value kepada konsumennya, antara lain: 1) menu makanan dan minuman kopi yang berkualitas; 2) harga terjangkau; 3)tempat kedai kopi yang mendukung untuk bekerja, berdiskusi, dan berkumpul; 4) harga yang terjangkau; dan 5) promo penjualan tiap bualnnya; 6) pelatihan kopi baik kelas maupun prifat.; 7) penjualan alat penyeduhan kopi.

c. Saluran Pelanggan (Channel) 
Saluranyang digunakan oleh DW Coffee Shopadalah mealuioutlet atau kedai sendiri. Selain itu konsumen juga dapat memperoleh produk DW Coffee Shop dengan pemesanan online melalui website.

d. Hubungan Pelanggan (Customer Relatonship)

DW Coffee Shop menjalin hubungan dengan konsumennya melalui media sosial yang memposting hal-hal yang terjadi di DW Coffee Shop dan memberikan pelayanan personal kepada pelanggan yang ingin belajar membuat kopi mereka sendiri, serta proses bertatap muka untuk menjalin interaksi langsung dengan konsumen.

e. Arus Pendapatan (Revenue Stream)

Pendapatan DW Coffee Shopberasal dari penjualan langsung makanan dan minuman di kedai, penjualan biji kopi dan peralatan penyeduhan kopi secara online atau langsung, dan pengadaan pelatihan kopi "coffee class". Diversifikasi pendapatan ini dilakukan oleh pemilik DW Coffee Shop dengan tujuan untuk memperluas sumber pendapatannya.

f. Sumber Daya Kunci (Key Resoures)

Sumber daya yang menjadi kunci bagi DW Coffee Shopantara lain:1) perjanjian suplaier biji kopi dan peralatan; 2) barista dan karyawan yang terlatih; 3) bangunan kedai; 4) website www.dwcoffeeshop.com; 5) sumber daya financial

\section{g. Aktifitas Kunci (Key Ativities)}

Hal-hal yang menjadi aktifitas DW Coffee Shopadalah: 1) proses produksi produk menu; 2) kegiatan pemasaran; 3) pengantaran pesanan kopi; dan 4) kegiatan pelatihan kopi.

h. Kemitraan Kunci (Key Partner)

DW Coffee Shopmenjalin kerjasama dengan suplaier dan roaster kopi. hubungan kerjasama juga dijalin dengan komunitas-komunitas dan akunakun endorsment sosial media.

i. Struktur Biaya (Cost Struscture)

DW Coffee Shop memiliki struktur biaya yang dibagimenjado tiga bagian, antara lain: 1) raw material cost; 2) operational cost; 3) non operational cost.Pembagian struktur biaya ini bertujuan untuk efektifitas kinerja keuangan.

\section{Analisis Peta Empati}

Analisis peta empati dilakkan unutk memperoleh gamabarn mengenai bagaimana wawasan konsumen terhadap Coffee Shop. Analisis ini dilakukan berdasarkan hasil wawancara kepada 30 orang responden yang merupakan pelanggan Coffee Shop.

\section{Apa yang Dilihat Konsumen}


Bagian ini memberikan gambaran mengenai apa yang dilihat oleh konsumen pada saat berkunjung atau mengkonsumi produk Coffee Shop. Hasil dari wawancara menunjukkan beberapa hal yang menurut konsumen penting. Hal utama yang menjadi perhatian konsumen adalah konsep dekorasi kedai dan tampilan menu, dari keseluruhan responden sebanyak 94\% menyatakan bahwa dekorasi, tampilan menu, dan pelayanan sangat mepengaruhi mereka saat mengunjungi sebuah Coffee Shop. Kemudian 60\% dari jumlah responden menyebutkan bahwa sosial media, kebersihan, kelayakan, dan kelengkapan fasilitas juga menjadi faktor yang dilihat. Selain itu $44 \%$ responden memperhatikan kuantitas dan varian menu yang disediakan oleh sebuah Coffee Shop . hal-hal lain yang disebutkan oleh responden seperti lokasi, harga, dan lain-lain hanya memiliki prosentase dibawah $10 \%$ dari keseluruhan jumlah responden.

\section{Apa yang Didengar Konsumen}

Selanjutnya adalah bagian dimana apa yang didengar oleh konsumen menggambarkan hal-hal yang memberi pengaruh dan informasi apa yang mempengaruhi konsumen. Sebagian besar responden menjawab bahwa informasi yang diterima merupakan informasi mengenai kondisi fisik dari kedai Coffee Shop itu sendiri dan cita rasa dari menu kopi yang ditawarkan, jumlah presentase responden yang manyatakan hal ini adalah $77 \%$.

Selain itu sosial media, harga dan tempat lokasi menjadi rekomendasi yang sering didengar mengenai kedai Coffee Shop, jumlah responden adalah $43 \%$ dari keseluruhan responden. Hal ini menunjukkan bahwa selain kondisi fisik dan rasa, harga dan lokasi juga menjadi informasi rekomendasi yang sering diterima oleh konsumen mengenai sebuah Coffee Shop.

\section{Apa yang Dipikirkan dan Dirasakan Pelanggan}

Pada bagian ini konsumen menggambarkan hal-hal yang menurut mereka adalah hal yang terpikirkan mengenai sebuah Coffee Shop. Berdasakan hasil wawancara, $89 \%$ responden menyatakan bahwa kenyamanan tempat, pelayanan, rasa dan kualitas merupakan hal yang sering dipikirkan dan dirasakan konsumen, kemudian postingan sosial media menjadi hal yang juga dipikirkan oleh konsumen (65\%). Sedangkan hal lain hanya mendapat prosentase dibawah $10 \%$ dari total keseluruhan responden.

Hasil wawancara menunjukkan bahwa penting bagi sebuah Coffee Shop untuk menyajikan produk-produk yang sesuai dengan ekspektasi konsumen serta menjaga kenyamanan dan pelayanan Coffee Shop tersebut. Hal ini bertujuan agar apa yang dipikrkan oleh konsumendapat terwujud sehingga akan memberikan kepuasan bagi konsumen.

\section{Apa yang Dikatakan dan Dilakukan Pelanggan}

Bagian ini menggambarkan apa yang dikatakan dan dilakukan responden setelah mengunjungi danmengkonsumsi kopi serta meu lainnya sebuah Coffee Shop. Tanggapan yang diberikan oleh responden bergantung pada kepuasan konsumen. Jika responden merasa puas maka mereka menyatakan akan datang lagi atau melakukan pembelian ulang, mengajak keluarga, teman dan kolega, serta melakukan posting pada akun media sosial. responden yang merasa puas akan memberikan informasi positif. Sedangkan jika responden tidak puas mereka akan memberikan informasi negatif. Sebanyak $71 \%$ responden menyatakan akan kembali lagi dan memberikan rekomendasi positif jika mereka 
merasa puas, sedangkan 32\% responden mengatakan bukan hanya tidak kembali namun juga memberikan rekomendasi negatif pada teman, keluarga, atau kolega. Selain itu sebanyak $72 \%$ responden menyatakan akan memposting kegiatan mereka di Coffee Shop pada akun media sosial yang dimiiki.

\section{Apa yang Menjadi Kerugian Konsumen}

Bagian ini menggambarkan hal yang menjadi kerugian atau hambatan bagi responden untuk berkunjung ke Coffee Shop dan mengkonsumsi minuman kopi. Responden memiliki jawaban yang beragam, mereka menyatakan bahwa faktor kesehatan, varian menu kopi yang ditawarkan, dan harga merupakan kerugian atau hambatan untuk berkunjung ke Coffee Shop dan mengkonsumsi minuman kopi.

Sebesar $62 \%$ responden menyatakan bahwa efek samping yang timbul setelah minum kopi menjadi kerugian bagi mereka. Selain itu sebagian responden juga menyatakan bahwa mereka mengalami kebosanan terhadap varian menu kopi (31\%).

\section{Apa yang Menjadi Perolehan Konsumen}

Bagian ini menggambarkan hal yang menjadi perolehan dan daya tarik konsumen dalam berkunjung ke Coffee Shop dan mengkonsumsi minuman kopi. Seluruh responden mengatakan bahwa hal yang diperoleh adalah sensasi yang berbeda saat berkunjung ke sebuah Coffee Shop dan mengkonsumsi kopi. 98\% responden menyebutkan bahwa cita rasa kopi yang diminum sambil bekerja, berdiskusi, atau berkumpul di tempat yang nyaman.

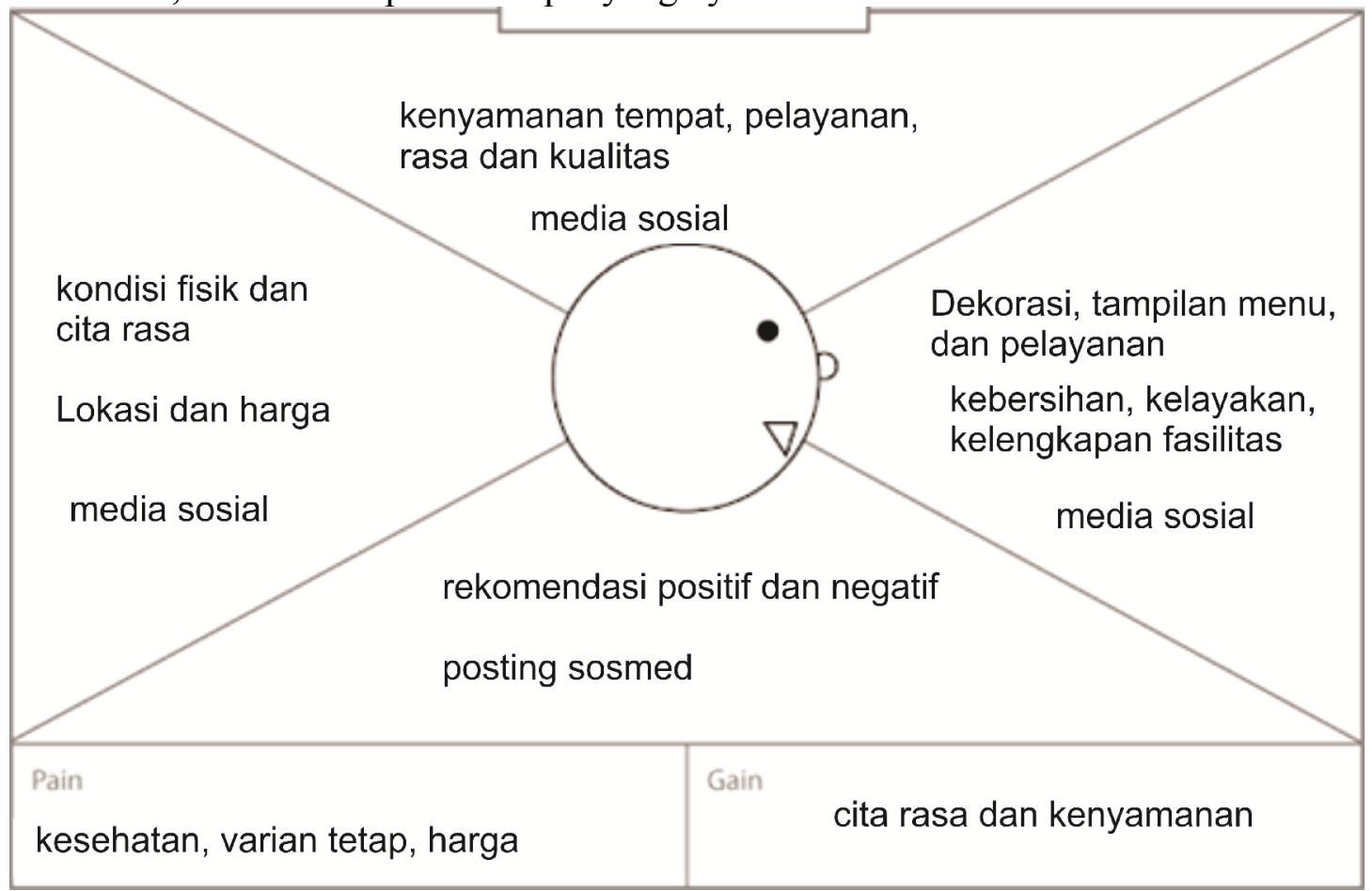

Gambar 1. Peta Empati Responden

\section{SIMPULAN}

Berdasarkan analisis yang dilakukan, penelitian ini menunjukan adanya pertumbuhan industri kuliner khususnya Coffee Shop di Kota Malang. Para paleku bisnis bersaing untuk dapat menjadi yang bertahan ditengah pertumbuhan Coffee Shop yang pesat. Namun, pertumbuhan tersebut ternyata belum diimbangi dengan penerapan 
model bisnis yang sesuai dengan kondisi saat ini dan mencakup wawasan yang dimiliki oleh konsumen Coffee Shop.

Hasil dari wawancara dengan pelaku bisnis dan konsumen Coffee Shop menunjukkan bahwa pelaku bisnis coffee shop baru sebagian memenuhi keinginan dan wawasan dari konsumen. Hasil analisis peta empati konsumen menunjukkan bahwa konsumen Coffee Shop sangat dekat dengan media sosial yang sudah menjadi bagian dari keseharian konsumen. Berdasarkan analisis kanvas model bisnis, dalam hal ini para pelaku bisnis sudah mampu menangkap peluang dan memanfaatkannya dalam model bisnisnya. Namun, pada analisis kanvas model bisnis bagian proporsi nilai (value proposition), dari kedua pelaku bisnis yang diteliti, kedua bisnis sama-sama menawarkan harga yang murah dan terjangkau bagi konsumennya, sedangkan dari hasil analisis peta empati konsumen menunjukkan bahwa harga bukanlah menjadi faktor yang prioritas bagi konsumen Coffee Shop.Hal ini menunjukkan bahwa masih kurangnya analisis yang komprehensif dan pehamanan seperti kanvas model bisnis dan peta empati konsumen oleh pelaku bisnis Coffee Shop di kota Malang untuk membentuk model bisnis yang baik dan memenuhi keinginan serta wawasan konsumen mengenai bisnis Coffee Shop.

Oleh karena itu, penggunanaan alat analisis usaha kanvas model bisnis dan peta empati diharapkan dapat diterapkan oleh para pelaku usaha dari segala macam jenis bisnis untuk menggambarkan bisnis yang akanatau telah dijalankan. Tujuan dari penggunaan alat analisis tersebut bertujuan untuk mendukung pengembangan bisnis agar bisnis dapat berjalan sesuai dengan kebutuhan, keinginan, serta wawasan konsumen secara efektif dan efisien.

\section{DAFTAR PUSTAKA}

Adiningsih, K, P. (2012). Analisis Kepuasan dan Loyalitas Konsumen Restoran Nasi Bebek Ginyo di Jakarta. Jurnal. MB-IPB

Asdhiana, I. M. (2014). Makan di Restoran Semakin Ngetren. http://travel.kompas.com/read/2014/04/04/1632122/Makan.di.Restoran.Sema kin.Ngetren Diakses 10 Mei 2014

Badan Pusat Statistik Kota Malang. (2017). Kota Malang Dalam Angka 2017. Malang: Badan Pusat Statistik Kota Malang.

Collins, J. C. dan Porras, J. I. 1996. Building Your Company's Vision. Harvard Business Review.

Dinas Pariwisata Kota Malang. (2016). Statikstik kepariwisataan 2016. Malang: Dinas Pariwisata Kota Malang.

Herlyana, E. (2012). Fenomena Coffee Shop sebagai Gejala Gaya Hidup Baru Kaum Muda. Thaqafiyyat, Vol. 13, No.1

Hisrich, R.D., Peters, P.M., Shepherd, A.D. (2013). Entrepreneurship. ( $9^{\text {th }}$ ed). New York: Mcgraw-Hill/Irwin.

Kotler, P., dan Keller, K. L. (2012). Marketing Management (14th ed.). Harlow: 
Pearson Education.

Soesatyo, N., Rumambi, L.N. (2013). Analisa Credibility Celebrity Endorser Model :Sikap Audience Terhadap Iklan Dan Merek Serta Pengaruhnya Pada Minat Beli “" Top Coffee”. Jurnal Manajemen Pemasaran Vol. 1, No. 2, 2013, 1-12

Murwani, E. (2012).'Eating Out' Makanan Khas Daerah: Komoditas Gaya Hidup Masyarakat Urban. E-Jurnal Manajemen Universitas Multimedia Nusantara.

Osterwalder, A., \& Pigneur, Y. (2010). Business Model Generation. Hoboken: John Wiley \& Sons, Inc.

Tim PPM Manajemen (2012). Business Model canvas: Penerapan di Indonesia. PPM Manajemen.

Subkhan. (2014). Orang Indonesia Habiskan Rp 17 Triliun Buat Jajan. DIkases 10 Mei 2014 dari http://www.tempo.co/read/news/2014/04/17/174571251/Orang-IndonesiaHabiskan-Rp-17-Triliun-buat-Jajan

Thompson, A. A., Peteraf, M. A., Gamble, J. E., dan Strickland, A. J. (2012). Crafting and Excuting Strategy: The Quest for Competitive Advantage: Concepts and Cases (18th ed.). New York: McGraw-Hill/Irwin 